\title{
O CORPO INDIGNO ${ }^{1}$
}

\author{
THE UNWORTHY BODY
}

\section{LE CORPS INDIGNE}

Rachele Borghi

\section{RESUMO}

Abordarei neste texto os corpos, mais especificamente os corpos fora de norma, esses corpos que o olhar héteropatriarcal sexista e capitalista considera como out of place, em particular do espaço público. Dos corpos que, evidentemente, é preciso colocar de lado, marginalizar, invisibilizar, excluir dos privilégios. Para fazer isso, eu vou lhes contar uma história. E porque sou feminista, vou partir de mim mesma. Eu gostaria de construir minha intervenção em torno da relação entre espaço, ordem social e dinâmicas de controle dos corpos, uma relação construída para manter os privilégios de sujeitos dominantes e o status quo social. Mas ao invés de me concentrar na denúncia de como a injustiça social foi construída também através do espaço e de seu uso e como cada um(a) de nós participa de forma mais ou menos consciente da legitimação ou da recusa das normas espaciais, vou me concentrar nas reações, nas ações e nas micropolíticas de enfrentamento, de desvio e de transbordamento do controle do corpo e da imposição de normas dominantes. Minha abordagem é a do transfeminismo queer, eu sou feminista, uma acadêmica feminista. Minhas pesquisas e meu trabalho como pesquisadora, isto é, o que eu vou propor são provenientes da epistemologia feminista que me ensinou que a divisão entre teoria e prática nos serve também para criar tipologias de conhecimento hierarquizado, deslegitimando tudo o que não se refere aos produtores de conhecimentos legítimos, com ferramentas consideradas "científicas".

PALAVRAS-CHAVE: Espaço. Corpo. Feminismo. Performance. Teoria queer.

\begin{abstract}
In this text I will discuss bodies, more specifically bodies out of the norm, these bodies that the heteropatriarchal sexist and capitalist gaze regards as out of place, in particular out of the public space. Bodies that, of course, must be placed aside, be marginalized, be turned invisible, be denied privileges. To do this, I'll tell you a story. And because I am a feminist, I start from myself. I would like to build my exposition on the relationship between space, social order and body control dynamics, a relationship built to keep the privileges of the dominant subjects and the social status quo. But rather than focus on the complaint of how social injustice was built also through space and its use and how each of us participates in a way more or less aware of the legitimacy or the refusal of spatial rules, I will focus on reactions, in actions and in the micropolitical confront, bypass and overflow of body control and the imposition of dominant norms. My approach is the queer transfeminism, I am a feminist, a feminist academic. My research and my work as a researcher, that is, what I will propose are from feminist epistemology. The feminist epistemology taught me that the division between theory and practice serves us to create hierarchical knowledge typologies, delegitimizing everything that does not refer to producers of legitimate knowledge with tools considered "scientific".
\end{abstract}

KEYWORDS: Space. Body. Feminism. Performance. Queer theory.

\footnotetext{
${ }^{1}$ Originalmente intitulado Le Corps Indigne, apresentado na forma de conferência em um curso de verão do projeto SIGNAL, do Centre International de Formation en Arts du Spectacle (CIFAS), de Bruxelas, em 10 de setembro de 2015. Traduzido por Maria Helena Lenzi e revisado por Fernando Coelho.
} 


\section{RÉSUMÉ}

Aujourd'hui je suis censée parler des corps, plus spécifiquement de corps hors-norme, de ces corps que le regard hétéro-patriarcal sexiste et capitaliste considère comme out of place, en particulier de l'espace public. Des corps qu'il faut, ça va de soi, écarter, marginaliser, invisibiliser, exclure des privilèges. Pour faire cela, je vais vous raconter une histoire. Et, parce que je suis féministe, je vais partir de moi. Je voudrais aujourd'hui construire mon intervention autour du rapport entre espace, ordre social et dynamiques de contrôle des corps, un rapport construit pour maintenir les privilèges des sujets dominants et le statu quo social. Mais plutôt que me concentrer sur la dénonciation de comment l'injustice sociale se construit aussi à travers l'espace et son usage et comment chacun.e d'entre nous participe de façon plus ou moins consciente à la légitimation des normes spatiales ou à leur refus, je vais me concentrer sur les réactions, les actions et les micropolitiques d'affrontement, de détournement et de dépassement du contrôle de corps et d'imposition des normes dominantes. Mon approche est celle du transféminisme queer, je suis donc une féministe, une universitaire féministe. Mes recherches et mon travail de chercheuse, c'est-à-dire ce que je vais vous proposer aujourd'hui, sont issus de l'épistémologie féministe. L'épistémologie féministe m'a aussi appris que la division entre théorie et pratique nous sert aussi à créer des typologies de connaissance hiérarchisées, délégitimant tout ce qui ne renvoie pas aux producteurs de connaissances légitimées, avec des outils considérés comme "scientifiques".

MOTS-CLÉS: Espace. Corps. Féminisme. Performance. Théorie queer.

\section{INTRODUÇÃO}

Hoje eu devo falar dos corpos; mais especificamente dos corpos fora de norma, desses corpos que o olhar hétero-patriarcal sexista e capitalista considera como out of place, em particular do espaço público. Dos corpos que, evidentemente, é preciso colocar de lado, marginalizar, invisibilizar, excluir dos privilégios.

Para fazer isso, eu vou lhes contar uma história. E porque sou feminista, vou partir de mim mesma. Vou desfrutar desse privilégio que tenho hoje, que é o de falar para um auditório que parece estar disposto a permanecer aqui e a me escutar por aproximadamente uma hora.

Eu gostaria de construir minha intervenção em torno da relação entre espaço, ordem social e dinâmicas de controle dos corpos, uma relação construída para manter os privilégios de sujeitos dominantes e o status quo social. Mas ao invés de me concentrar na denúncia de como a injustiça social foi construída também através do espaço e de seu uso e como cada um(a) de nós participa de forma mais ou menos consciente da legitimação ou da recusa das normas espaciais, vou me concentrar nas reações, nas ações e nas micropolíticas de enfrentamento, de desvio e de transbordamento do controle do corpo e da imposição de normas dominantes. Minha abordagem é a do transfeminismo queer, eu sou feminista, uma acadêmica feminista. Minhas pesquisas e meu trabalho como pesquisadora, isto é, o que eu vou propor hoje, são provenientes da epistemologia feminista.

A epistemologia feminista me abriu os olhos para o fato de que a produção do conhecimento não é objetiva, mas que ela se liga aos produtores de tais conhecimentos e que, quando a produção do conhecimento está intimamente ligada ao poder e quando o poder era (e ainda é frequentemente o caso) exercido pelos homens, é evidente que o saber não é objetivo, mas corresponde a um posicionamento masculino (e mais precisamente ao 
olhar masculino) e dominante. E quando dizemos dominante, estamos dizendo branco, ocidental e burguês. Então, boa sorte aos empiristas... A epistemologia feminista me ensinou que a divisão entre teoria e prática nos serve também para criar tipologias de conhecimento hierarquizado, deslegitimando tudo o que não se refere aos produtores de conhecimentos legítimos, com ferramentas consideradas "científicas". Refiro-me à ideia de que existe um conhecimento "puro", cuja imparcialidade e universalidade são garantidas por sujeitos como professores, médicos, cientistas em geral. Desconstruindo esse ponto de vista, eu aprendi a integrar a subjetividade no meu trabalho de pesquisa e a me posicionar em relação ao meu campo.

A teoria queer, que, por uma razão geracional, é o que caracteriza o feminismo em que me reconheço (eu nasci em 1976, portanto me formei nos anos da terceira onda do feminismo, após Teresa de Lauretis em 1990) em Santa Cruz, na Universidade da Califórnia, na conferência "Lesbian and gay sexualities" ter utilizado o termo "queer" (até esse momento utilizado como sinônimo de bizarro, estranho, pederasta...) ao lado da palavra "teoria". Essa intervenção foi publicada na revista Differences e traduzida para o francês por Marie-Hélène Bourcier em 2007 no livro Teoria queer e culturas populares. "Q.[ueer] T.[heory] chama a atenção por dois aspectos: o trabalho conceitual e especulativo que implica a produção do discurso e a necessidade de um trabalho crítico que consiste em desconstruir nossos próprios discursos e nosso silêncio construído" (DE LAURETIS, 2007, p. 97-98). De Lauretis mostrou a diferença entre o seu uso do termo queer e aquele do Queer Nation. De fato, o termo já havia começado a se desenvolver junto a grupos militantes com um valor de auto-definição através da subversão do insulto a partir dos anos 1980.

Se a teoria queer reúne a pesquisa teórica sobre o tema das sexualidades na segunda fase dos estudos culturais, marcados pelo feminismo e pela crítica pós-colonial, criticando a heteronormatividade dominante e a repressão social dos subalternos, ao legitimar ao mesmo tempo a sua presença como sujeitos ativos do saber (ver BOURCIER, 2001; 2011), o termo queer se difunde dentro e fora da academia, dando vida a uma proliferação de usos, tanto no meio acadêmico quanto no meio militante. Esse contexto de produção de subculturas influenciou a reflexão sobre a pesquisa, sobre o campo e seus métodos.

Utilizar em minhas pesquisas a metodologia queer significa, como explicam bem Borghi e Prieur (2014, comunicação oral):

\footnotetext{
Apoiar-se nos saberes situados feministas (posicionalidade), sobre a reflexividade da pesquisa (estudar a maneira pela qual construímos a pesquisa mas também a maneira de fazer o campo) e também o "care" na pesquisa (como realizar uma investigação e como fazer uso dos dados sem colocar em perigo as pessoas entrevistadas e lhes retribuindo algo).
}

Porque acredito que o pessoal é ainda político, eu farei isso explicitando a minha experiência e o meu posicionamento. 
Primeiramente, gostaria de partir de uma evidência: o espaço público não é neutro. $O$ espaço não é apenas um pano de fundo, um cenário no qual ações humanas acontecem, mas é também um produtor de significados e um reprodutor de mecanismos e de dinâmicas sociais. No entanto, a consideração do papel do espaço como vetor das normas sociais ligadas ao gênero e às sexualidades não é evidente. Ora, o espaço público é concebido, gerido e modelado sobre a base de uma concepção binária rígida (homem-mulher, homossexual-heterossexual, etc.) 〈http://goo.gl/weWlKH>.

Dessa forma, a natureza de gênero do espaço social é ocultada pela naturalização da divisão entre espaço público e espaço privado, reflexo da divisão da vida social entre esferas pública e esfera privada. A heteronormatividade do espaço social é ocultada por uma suposta "neutralidade" e uma ideia mítica da ágora.

O espaço, portanto, legitima ou sanciona e, dessa forma, constrói a norma. Consequentemente, nossa prática espacial pode apoiar, legitimar e reproduzir, de forma mais ou menos consciente, essas normas.

Parece mais evidente, portanto, que os espaços desempenhem um papel importante na reprodução e na naturalização das estruturas de poder; e é no corpo, nos nossos corpos, que as dinâmicas de controle social têm sua aplicação (FOUCAULT, 1975).

Quem é, então, o sujeito que, de pleno direito, habita o espaço público? Não se trata de um sujeito neutro, mas bem posicionado: é o sujeito dominante, isto é, do sexo masculino, branco, ocidental, heterossexual, bem de vida, saudável e jovem. Esse sujeito determina a norma, bem como o que é considerado como fora da norma.

O espaço público, portanto, adquire um caráter fortemente normativo, que sanciona e exclui os sujeitos e os corpos que não correspondem às normas sociais. Quais são os corpos out of place? São os corpos que incorporam os modos de vida que não aderem ao que é considerado "normal". Sua estigmatização e exclusão espacial contribui para a reprodução das noções de cidadania e de direito com base na normatividade, e até mesmo da heteronormatividade (HUBBARD, 2001; JACKSON, 2006). Para esses sujeitos, a prática dos espaços públicos pode se tornar muito constrangedora (e geradora de ansiedade se pensarmos nas agressões verbais e físicas).

A perspectiva até então traçada nos ajuda a desconstruir a evidência segundo a qual o espaço público é um espaço neutro e universal e o fato de que todo indivíduo que o atravessa pode percorrê-lo e se apropriar dele de maneira idêntica/igual. Contudo, essa tomada de consciência não pode ser um ponto de chegada, mas tornar-se um ponto de partida. Se somos capazes de reverter as perspectivas, podemos transformar em forte o que é considerado fraco, desviar os discursos dominantes e criar os espaços de inversão, de transgressão das normas dominantes heterossexistas patriarcais ainda que esses espaços sejam frequentemente temporários. 
Essa perspectiva tem três palavras-chave: corpo, performance e espaços íntimos. Começamos com o corpo. O corpo está em relação contínua com o espaço. Não somente o corpo está no espaço, mas ele é também espaço (JOHNSTON; LONGHURST, 2010). Por conseguinte, o corpo é um espaço social, está em relação com outros espaços e participa da produção do espaço. $\mathrm{O}$ fato de que ele seja continuamente colocado em relação com o espaço obriga-nos a

[...]reconhecer que os indivíduos em sociedade estão submetidos a determinações, ou mesmo opressões, relacionadas às suas características físicas. $\mathrm{O}$ corpo humano não pode ser ignorado nas pesquisas sobre a concepção que os indivíduos criam acerca do perigo, da distância, da violência, da hostilidade do meio de vida, da saúde e sobre as práticas espaciais que eles realizam (BARTHE-DELOIZY, 2003, p. 213).

Desse modo, os corpos têm um enorme potencial e os corpos fora da norma ainda mais... porque eles possuem um forte potencial de subversão que pode permitir a transgressão das normas que regulam os espaços públicos.

Se ao corpo adicionamos a performance, percebemos formas de ativismo e de resistência em que utilizamos o próprio corpo como suporte à ação através de performances no espaço público que permitem tornar visíveis as relações de dominação e de injustiça social, por isso falamos de uma nova arte de militar.

Há muitos exemplos como esse, e muitos livros e artigos foram escritos recentemente. Hoje, eu gostaria de mostrar-lhes exemplos de performances realizadas no espaço público por sujeitos ativistas que introduziram o gênero, mas também as sexualidades nas reivindicações, bem como nas maneiras de levar ao espaço público as suas reivindicações.

Evidentemente, aqui o corpo do(a) ativista é central: o corpo fora da norma (corpos de mulheres, de pessoas transpédégouines ${ }^{2}$, corpos não-brancos, corpo anormais, corpos loucos) torna-se a incorporação das reivindicações e suporte da ação. A performance dos corpos permite ocupar o espaço público.

Eu uso o conceito de performance em uma perspectiva queer, e mais particularmente com uma metodologia de pirata "scavenger methodologies" (HALBERSTAM, 1999). Isso significa que no meu entendimento o conceito de performance faz referência ao mesmo tempo à Butler (cujo livro Gender Trouble de 1990 é um marco da terceira onda do feminismo e da teoria queer), mas também ao seu uso na antropologia e na arte. Butler mostrou como a performance é uma atribuição normativa que, por meio da repetição e da reiteração dos gestos, das posturas, das palavras através do corpo, naturaliza e reproduz o gênero; a performance cita os gestos, as posturas, as palavras e os reitera, os repete. Para Butler, o gênero é um enunciado performativo que tem a capacidade de criar o que nomeia.

O gênero é, portanto, uma forma de performance, porque ele não existe antes de ser atuado. Ele não é uma qualidade do sujeito; ele é a expressão da norma. O que permite à

2 Expressão utilizada em francês para se referir a LGBT. Trans-pédé-gouine significa, respectivamente, transexuais e transgêneros, gays e lésbicas [nota da tradutora].

\begin{tabular}{l|l|l|l|l|l|l} 
(C) ETD-Educ. Temat. Digit. & Campinas, SP & v.18 & n.4 & p. 789-801 & out./dez.2016 & ISSN 1676-2592
\end{tabular}


norma existir é o fato de ser dita e repetida. Nesse contexto, o sexo é o antecedente artificial do gênero; ele não é "natural", mas, ao contrário, é "naturalizado" e invisibilizado pelo poder do discurso. Consequentemente, o gênero ainda é uma imitação, mas uma imitação sem um modelo original: é o ato de imitação, a performance, a citação, que dá corpo ao original antecedente (ARFINI, 2011). Segundo sua reflexão, o “doing”, o "fazer" do discurso, os conhecimentos pré-constituídos e as repetições produzem os sujeitos sociais. Portanto, as identidades não existem antes da performance (GREGSON; ROSE, 2000).

Ao mesmo tempo, o conceito de performance remete à operacionalização ou à instalação de uma criação. É uma ação simbólica pela qual o(a) militante/artista/ativista/artivista torna visível o invisível por meio de recursos estéticos (formas, cores, materiais) e também através do seu corpo. A performance permite abrir espaços (mais ou menos efêmeros, mais ou menos temporários) de criação, através de ações simbólicas que tornam visível o invisível. Ela permite analisar a relação entre os indivíduos e as normas sociais, isto é, os processos de interiorização e as dinâmicas de reprodução das normas (de "raça", de classe, de gênero, sexuais). O corpo torna-se o lugar no qual a performance toma forma, um lugar habitado, reapropriado, o primeiro espaço de elaboração da reflexão, da criação, da reivindicação. A performance designa, portanto, um corpo em ação que perpetuamente produz uma nova realidade (THRIFT, 2000; CHAPUIS, 2010).

Se a performatividade é compulsória, ela pode representar um recurso para a mudança social e política, porque nós sempre podemos reverter o valor da performance e usá-la para afirmar, mostrar, tornar visível ou simplesmente chamar a atenção para algo. Esse é o caso, por exemplo, dos hate speeches, dos insultos que podem ser usados de maneira distorcida, criativa e positivamente desviante (BUTLER, 2008). A performance pode, portanto, subverter a norma ao invés de a reproduzir. Como? Pelos mesmos meios da performatividade: através da repetição, da reiteração "inadequada", do afastamento do performativo.

Essa concepção do corpo desprezado como ferramenta de resistência necessita uma aprendizagem, o que significa que há uma operação prévia: a reapropriação de seu próprio corpo, despossuído pelo patriarcado e pelas normas heterossexistas. Habitar os corpos gordos, feios, inadequados, excessivos, provocantes, eufóricos; os corpos nus, corpos fora de categoria, fora do local, fora da norma, os corpos trans, sem gênero, loucos, desejantes, os corpos anormais, os corpos loucos, os corpos de vadia. Habitar esse tipo de corpo, isso se aprende. Reapropriar-se desse corpo significa aprender a vivê-lo, a habitá-lo, como o feminismo nos ensinou. Essa é uma etapa fundamental para poder ocupar o espaço público. E aqui chegamos à terceira palavra-chave: Espaços íntimos, caracterizados por uma dimensão emocional e afetiva. Se desconsiderarmos o sistema binário com o qual aprendemos a conceber o espaço e, portanto, a regular nossos comportamentos e atitudes, para oprimir nossos desejos, para julgar o que está no lugar correto ou o que está deslocado, ou seja, se tentarmos esquecer esse binômio espaço público/espaço privado, poderemos, talvez, ler os espaços não como continentes divididos de forma rígida uns dos outros e 
dentro dos quais podemos armazenar coisas e pessoas, situações e comportamentos, com cada coisa em seu lugar.

Ao contrário, talvez possamos lê-los como caixas abertas, ou, ainda melhor, como vasos comunicantes, que dão vida aos spaces in between, que não são nem uma coisa nem outra, mas o resultado das interações entre os diferentes elementos que caracterizam o espaço e os corpos que o atravessam. Se olharmos o espaço dessa maneira, podemos pensar os espaços como um continuum. Não haverá mais uma fechadura nas nossas próprias portas, lá onde iremos banir a vida dita "privada", que devemos pensar como um espaço fechado à parte do resto do mundo, o único lugar para lavar a roupa suja, uma perspectiva que nos autoriza a pensar que o que acontece no interior não diz respeito aos outros, não é político.

A porosidade dos espaços nos convida, ao contrário, a pensar que as dimensões ditas privadas e públicas de nossas vidas podem se contaminar. E é assim que a casa se torna um lugar de intimidade e de partilha, da intimidade e da militância, um espaço que pode se tornar um espaço coletivo, juntamente com os espaços comuns, lugares privilegiados de sociabilidade; espaços de reunião onde a vida social do grupo acontece e onde as normas sociais que regulam os espaços de "fora" são suspensas ou são experimentadas como menos restritivas. Esses são espaços (casas, locais de militância etc.) muito importantes para as minorias, porque eles permitem o desenvolvimento da sociabilidade, da partilha de experiências e do empoderamento (associações locais, centros comunitários, mas também bares, clubes, etc.). Esses são espaços de troca, de partilha, que se tornam espaços de aprendizagem (das modalidades de militância, mas também das modalidades para se reapropriar do seu próprio corpo) também através da realização de ateliês.

A dimensão do ateliê é central nesse discurso, porque é nos ateliês que os indivíduos podem experimentar. O corpo torna-se um laboratório de práticas e de experimentação. Seu corpo e seu corpo em interação com os outros. Nos ateliês, o corpo individual torna-se também um corpo coletivo. Essa dimensão íntima é muito importante porque permite criar relações, redes, construir relacionamentos que são necessários para ganhar confiança e para o empoderamento que permite a ação (coletiva ou individual) na esfera pública. Nos ateliês, portanto, podemos construir intimidades compartilhadas, experimentar formas de empoderamento e estratégias de resistência e de criação de contre-productions narratives.

\section{O QUE A RELAÇÃO ENTRE ESPAÇO, PERFORMANCE E CORPO NOS TRAZ?}

Ela nos permite abordar a questão da relação das minorias com o espaço público e analisar o processo de apropriação do espaço. Isso nos permite ver em que medida é possível criar espaços de suspensão das normas sociais, espaços benevolentes (PRIEUR, 2015).

Em segundo lugar, ela nos permite agir no espaço. 
Terceiro aspecto: podemos partir de concepções binárias da relação com o espaço (público/privado) e repensar essas relações, introduzindo a dimensão íntima que, quando está fortemente ligada ao desejo e à sexualidade, nunca tem lugar. Ademais, a articulação entre espaços e corpos nos permite tomar consciência da relação mútua de mudança, considerando a materialidade dessa relação.

Finalmente, esse raciocínio nos permite desvendar o caráter heteronormativo do espaço público e das instituições (escola, hospital, universidade, etc.).

Veremos agora exemplos que envolvem o recurso à tactical frivolity, <https://goo.gl/P2hdD6 > o fato de enfrentar a polícia durante as manifestações de maneiras não esperadas (ironia, jogos, etc.), ou seja, com expressões corporais que não esperamos, des-locadas (out of place).

Podemos ver nos die-in ${ }^{3}$ do AIDS Coalition to Unleash Power (ACT UP) um exemplo que faz referência, mas também eu diria que já existem precedentes, notadamente nas muitas manifestações do movimento feminista das sufragistas bem como das ativistas da década de 1970 até hoje.

Existem vários exemplos: da Barbe às Tumultueuses, das performance nos transportes às marchas noturnas, à Marcha das Vadias, às drag kings e todas as masculinidades e feminilidades não-dominantes e reivindicadas, até o Pornoativismo. Silvia Corti, conhecida como Slavina (http://malapecora.noblogs.org), fala de pornoativismo em relação a um conjunto de ações performativas que usam o corpo nu como suporte da ação e que fazem as sexualidades dissidentes visíveis, declaradas e reivindicadas. Os corpos dos(as) pornoativistas são corpos políticos sexuais, desejantes, que introduzem o elemento da sexualidade na militância. Uma vez feita a revolução no quarto de dormir, é hora de colocar o quarto de dormir no coração da revolução (Slavina). A sexualidade quase nunca é explicitada na militância, é por isso que o pornoativismo a explicita e a utiliza (ver, por exemplo, urban porn: 〈http://goo.gl/P0Dz6h〉.

O pós-porno é um exemplo. “O pós-porno é uma concatenação transversal que penetra as mais diversas esferas da sexualidade e da produção de imagens, seja na Internet ou nas indústrias culturais de massa, na arte ou na teoria, na micro como em macro-política" (STÜTTGEN, 2007, p. 278). É por isso que eu me interesso pelo pós-porno não como forma de arte, mas sobretudo como um movimento político (fluido, não homogêneo, formado por práticas e pontos de vista diferentes). Ou talvez seria melhor dizer como uma forma de política.

De acordo com Marie Helene/Sam Bourcier (2005, pp. 378-379),

${ }^{3}$ Protestos em que as pessoas deitam-se no chão simulando estarem mortas [nota da tradutora]. \begin{tabular}{l|l|l|l|l|l} 
(C) ETD - Educ. Temat. Digit. & Campinas, SP & v.18 & n.4 & p. 789-801 & out./dez.2016
\end{tabular} 
A emergência de um movimento e de uma estética pós-pornográfica (pós-porno) ao final do século XX constitui uma crítica da razão pornográfica ocidental. Ela pode ser analisada como um 'discurso de retorno', para usar os termos de Foucault, vindo das margens e das minorias da pornografia dominante: trabalhadores(as) do sexo, indivíduos que se prostituem, gays, lésbicas, BDSM (bondage, disciplina e sadomasoquismo), queers, trans, desviantes no geral assumidos como tais. O gatilho pós-porno igualmente consiste em uma desconstrução e em uma desnaturalização da pornografia moderna como tecnologia de produção da 'verdade do sexo', dos corpos e dos gêneros (masculino, feminino) que não teriam sido possíveis sem a contribuição das teorias feministas, pós-feministas, pró-sexo e queer.

Pornoacademicismo, ou como integramos a sexualidade e o corpo na instituição e nos mecanismos de produção de conhecimento. Um exemplo é o uso da linguagem performativa com Fuck my brain, seminários organizados por Bourcier em Paris.

Um segundo exemplo me diz respeito. Como feminista, eu parto de mim e de meu posicionamento que é aquele de uma pessoa que foi pesquisadora não efetiva (por 13 anos), e que agora é titular. $\mathrm{O}$ espaço público que eu sinto dizer mais respeito a mim é o da produção do saber. É por essa razão que eu decidi queerizar o espaço público da universidade, ou seja, criar uma porosidade entre os espaços de dentro e os de fora da universidade.

Eu trabalhava nas performances pós-porno no espaço público como um exemplo de criação de espaços de suspensão da norma. Eu imediatamente entrei em conflito com a norma disciplinar (a geografia) e tive que lidar com suas reações em relação ao meu sujeito, um "dirty topic" constrangedor que diz respeito a sujeitos (minhas pesquisas) com corpos e sexualidades fora da norma, dissidentes. A coisa mais simples era deslegitimar o meu trabalho como "não-geográfico". Eu me interrogava sobre a questão da relação entre pesquisa acadêmica e militância, sobre a relação no campo e sobre as formas de divulgação dos resultados de pesquisa para além da comunidade "científica".

Então eu pensei em usar os meios que estudei (a performance) e o suporte (o corpo) para experimentar novas modalidades de difusão dos resultados das pesquisas (geográficas). Então eu realizei o projeto/personagem Zarra Bonheur:

Era uma vez uma pesquisadora universitária-politópica-queer-feminista-militantedissidente sexual. Um dia ela percebe que sua criatividade não deve necessariamente permanecer relegada a artigos científicos. Ela decide liberar os temas, as reflexões, as teorias e as práticas de pesquisa do papel impresso como a única expressão aceita e legítima de comunicação científica e transforma suas pesquisas sobre gênero, sexualidades, corpos e dissidências em performances coletivas. Zarra Bonheur nasce, performer-pesquisadora-politópica-pornoativistaqueer-feminista-ativista dissidente sexual, resultado da contaminação Do it Yourself e do amor transmitido por seus amigos.

Zarra Bonheur traduz as pesquisas científicas em performances. O objetivo é romper os limites entre os contextos (científico/militante), as produções (cultura erudita/cultura pop), os lugares (universidade/sala de teatro, ocupação, associação), as expressões (palestra/performance) e produzir espaços de subversão/transgressão das normas. Por essa razão, Zarra Bonheur tornou-se um coletivo do qual Silvia Corti, conhecida como Slavina (testemunha privilegiada de minha pesquisa de campo), é parte. Zarra Bonheur trabalha nos 
interstícios para criar spaces in between. É o caso do Porno trash, uma performance criada a partir das minhas pesquisas sobre a relação entre corpo e espaço e sobre a representação/percepção da nudez no espaço público. Cada performance se transforma de acordo com os lugares e as pessoas envolvidas que mudam o tempo todo. É por essa razão que Zarra Bonheur não representa uma pessoa, mas um projeto coletivo da dissidência, de resistência, de experimentação e de pornoativismo (acadêmico).

Algumas das performances possibilitaram uma reflexão sobre o peso das normas, sobre o direito de tornar visível o corpo do(a) pesquisador(a) e o que é considerado lícito/ilícito. Eu queria, no início, experimentar a questão dos limites, a percepção da nudez no meio acadêmico e transformar em performance as problemáticas epistemológicas (a relação entre o pesquisador e seu campo, o voyeurismo da pesquisa, a não restituição das pesquisas aos contextos estudados e aos sujeitos envolvidos, a formação de um discurso científico legítimo que corre o risco de invisibilizar os discursos produzidos a partir do interior, a invisibilização do corpo do pesquisador, o qual se espera que seja formado somente pela sua cabeça, o fato de que uma conferência é também uma performance) que normalmente se espera que tratemos apenas por meios legítimos: com um slide de power point ou um artigo em uma revista "científica".

Durante uma conferência na Universidade de Bordeaux, em que fui convidada para falar a respeito da minha pesquisa sobre pós-porno, fui tirando a roupa ao longo de minha intervenção. Eu utilizei as ferramentas da performance acadêmica (power point, microfone, caneta em minhas mãos) e as linguagens científicas para criar um curto-circuito entre a mensagem, a referência e o código.

O vídeo foi postado na internet pelos(as) organizadores(as) do colóquio em fevereiro de 2013, mas somente quando fui admitida na Sorbonne (em maio de 2013) o apedrejamento midiático começou, e também os rumores mais ou menos violentos na Universidade. O vídeo foi divulgado em vários sites da direita, católicos, conservadores, que anunciam a colonização queer da universidade francesa e a decadência moral da instituição (BALDO, 2014).

Apesar da omissão ou mesmo recusa de muitos colegas, do entusiasmo de outros e da indiferença em relação a uma questão considerada, em última análise, "não grave" ou "não significativa", atualmente é difícil avaliar os efeitos. Por outro lado, Zarra Bonheur pode potencialmente suscitar uma discussão sobre os limites do conhecimento acadêmico, do engajamento do pesquisador e sobre quem tem o direito de decidir o que é in place ou out of place (BORGHI; BOURCIER; PRIEUR, 2016). 


\begin{abstract}
A marginalidade é um lugar radical de possibilidade, um espaço de resistência. Essa marginalidade que eu defino como espacialmente estratégica para a produção de um discurso contra-hegemônico está presente não só nas palavras mas também nos modos de ser e de viver. Eu não me refiro, por conseguinte, a uma marginalidade que poderíamos perder - deixar ou abandonar - à medida que nos aproximamos do centro, mas sim a um lugar onde poderíamos viver, ao qual permaneceríamos fiéis, porque é disso que nossa capacidade de resistência se nutre. Um lugar capaz de nos oferecer a possibilidade de uma perspectiva radical a partir da qual olhar, criar e imaginar alternativas e novos mundos (HOOKS, 1991).
\end{abstract}

\title{
REFERÊNCIAS
}

ARFINI, Elisa. Doing gender, ovvero: che ne facciamo del genere? In: BORGHI, Liana; MANIERI, Francesa; PIRRI, Ambra (Orgs.). Le cinque giornate lesbiche in teoria. Roma: Ediesse, 2011. 207 p. Disponível em: 〈http://goo.gl/FFqleU >. Acesso em: 07 set. 2016.

BALDO, Michela. When the body of the queer researcher is "trouble". Lamba Nordica, França, n. 02, p. 118-132. 2014. Disponível em: 〈http://goo.gl/j4Ng1i >. Acesso em: 07 set. 2016. ISSN 2001-7286.

BARTHE-DELOIZY, Francine. Géographie de la nudité: être nu quelque part. Rosny-sousBois: Bréal, 2003. 239 p. Disponível em : 〈http://goo.gl/aiyMrU〉. Acesso em : 07 set. 2016.

BLIDON, Marianne. Genre et sexualité: deux impensés de la géographie politique française. In: ROSIÈRE, Stéphane. et al. (Org.) Penser l'espace politique. Paris: Ellipses, 2009. p. 5468.

BLUNT, Alison; WILLS, Jane. (Orgs.). Dissident geographies: an introduction to radical ideas and practice. New Jersey: Prentice Hall, 2000. 212 p. Disponível em :

<http://goo.gl/hx681n >. Acesso em : 07 set. 2016.

BORGHI, Rachele. Post-porn. Rue Descartes, França, v. 03, n. 79, p. 29-41. 2013. Disponível em : 〈http://goo.gl/1yk0um>. Acesso em : 07 set. 2016. ISSN 1144-0821.

BORGHI, Rachele. L'espace à l'époque du queer: contaminations queer dans la géographie française. Revue PolitiQueer, França, p. 14-26. 2014. Disponível em: <http://goo.gl/Bndb0r>. Acesso em: 07 set. 2016. ISSN 2368-0733.

BORGHI, Rachele; PRIEUR, Christophe. Performing academy: réélaboration des théories et pratiques queers. In: JOURNÉE D'ÉTUDE THÉORIES ET ÉPISTÉMOLOGIES DANS LE CADRE DU SÉMINAIRE DOCTORAL CECILLE. Anais eletrônicos... Université Lille 3. 2014.

BORGHI, Rachele; BOURCIER, Marie-Helène; PRIEUR, Christophe. Performing academy: feedback and diffusion strategies for queer scholactivists in France. In: BROWN, Gavin; BROWN, Kath. (Orgs.). The routledge research companion to geographies of sex and sexualities. Farnham: Ashgate, 2016. 542 p. Disponível em: 〈http://goo.gl/vO4a1N〉. Acesso em: 07 set. 2016. 
BOURCIER, Marie-Helène. Postpornographie. In: DI FOLCO, Philippe; CARRIÈRE, JeanClaude (Orgs.). Dictionnaire de la pornographie. Paris: PUF, 2005. p. 378. Disponível em : <http://goo.gl/0lLemf >. Acesso em: 07 set. 2016.

BOURCIER, Marie-Helène. Queer Zones. Politiques des identités sexuelles. Paris: Balland. 2005.

BOURCIER, Marie-Helène. Queer Zones 2. Sexpolitiques. Paris: La Fabrique. 2006.

BOURCIER, Marie-Helène. Queer Zones 3. Identités, cultures, politiques. Paris:

Amsterdam. 2011.

BUTLER, Judith. Le pouvoir des mots: discours de haine et politique du performatif. Paris: Amsterdam, 2008.

BUTLER, Judith. Le Pouvoir des mots. Politique du performatif. Paris: Amsterdam. 2004.

BUTLER, Judith. Trouble dans le genre. Paris: La Découverte, 2005.

BUTLER, Judith. Ces corps qui comptent: de la matérialité et des limites discursives du sexe. Paris: Amsterdam, 2009.

DE LAURETIS, Teresa. Théorie queer et cultures populaire. Paris: La dispute, 2007.

DE LAURETIS, Teresa. Introduction to the conference Queer theory: lesbian and gay sexualities. Differences, França, v. 03, n. 02, p. 03-13. 1991.

FOUCAULT, Michel. Surveiller et punir. Paris: Gallimard, 1975. 313 p. Disponível em : <http://goo.gl/KGdTLO>. Acesso em : 07 set. 2016.

CHAPUIS, Amandine. Performances touristiques. D'une métaphore à un cadre de pensée géographique renouvelé. Mondes du Tourisme, França, n. 02, p 44-56. 2010. Disponível em : <http://goo.gl/QIQwdH >. Acesso em : 07 set. 2016. ISSN 2492-7503.

GREGSON, Nicky; ROSE, Gillian. Taking butler elsewhere: performativities, spatialities and subjectivities. Environnement and Planning D: Society and Spaces, n. 18, p. 433-452. 2000. Disponível em: 〈http://goo.gl/2Ij6Mm>. Acesso em: 07 set. 2016. ISSN 1472-3433.

HALBERSTAM, Jack. Female Masculinity. Durham: Duke University Press, 1999. 344 p. Disponível em: 〈http://goo.gl/R3gHec > Acesso em: 07 set. 2016.

HOOKS, Bell. Yearning: race, gender and cultural politics. London: Turnaround, 1991. 236 p. Disponível em: 〈http://goo.gl/ytbLDJ>. Acesso em: 07 set. 2016.

HUBBARD, Phil. Sex zones: intimacy, citizenship and public space. Sexualities, n. 04, p. 51-71. 2001. Disponível em: 〈http://goo.gl/Zw1GMd>. Acesso em: 07 set. 2016. ISSN 14617382. 
ION, Jacques; FRANQUIADAKIS, Spyros; VIOT, Pascal. Militer aujourd'hui. Paris: Autrement, 2005.

JACKSON, Stevi. Interchanges: gender, sexuality and heterosexuality: the complexity (and limits) of heteronormativity. Feminist Theory, v. 01, n. 07, p.105-121. 2006. Disponível em: <http://goo.gl/9SjOOf >. Acesso em: 07 set. 2016. ISSN 1741-2773.

JOHNSTON, Lynda; LONGHURST, Robyn. Space, place, and sex: geographies of sexualities. Lanham, MD: Rowman and Littlefield, 2010. 208 p. Disponível em: <http://goo.gl/o0B6FW>. Acesso em: 07 set. 2016.

PRIEUR, Cha. Des géographies queers au-delà des genres et des sexualités?

EspacesTemps.net, n. 20. 2015. Disponível em : 〈http://goo.gl/1eiZsS $\rangle$. Acesso em: 07 set. 2016. ISSN 0339-3267.

STÜTTGEN, Tim. Ten fragments on a cartography of post-pornographic politics. In: JACOBS, Katrien; JANSSEN, Marije; PASQUINELLI, Matteo. (Org.). C'lickme: a netporn studies reader. Institut of Network Cultures, 2007. p. 277-282. Disponível em :

<http://goo.gl/2tmQWo $>$. Acesso em : 07 set. 2016.

THRIFT, Nigel. Afterwords. Environment and Planning D: Society and Space, v. 18, 2000. Disponível em: 〈http://goo.gl/X8DBKq>. Acesso em: 07 set. 2016. ISSN 1472-3433.

VOLVEY, Anne. Le corps du chercheur et la question esthétique dans la science géographique. L'Information géographique, v. 78, p. 92-117. 2014. Disponível em : <http://goo.gl/L2vqkF>. Acesso em: 07 set. 2016. ISSN 1777-5976.

\section{RACHELE BORGHI}

Professora do curso de Geografia da Universidade de Paris IV - Sorbonne, Paris Universidade de Paris IV - Sorbonne, Paris. E-mail: rachele.bor@gmail.com

Recebido em: 07/09/2016

Aprovado para publicação em: 20/09/2016

\section{Como citar este documento:}

BORGHI, Rachele. O corpo indigno. ETD - Educação Temática Digital, Campinas, SP, v. 18, n. 4, p. 789 801, nov. 2016. ISSN 1676-2592. Disponível em: <http://periodicos.sbu.unicamp.br/ojs/index.php/etd/article/view/8646439>. Acesso em: 16 nov. 2016. doi:http://dx.doi.org/10.20396/etd.v18i4.8646439. 